\title{
Changes in the Orbital Tissues and Muscles Dysthyroid Ophthalmopathy
}

\author{
G. M. BLEEKER \\ Amsterdam, The Netherlands
}

\begin{abstract}
Summary
The mysterious background of Graves' Disease is gradually disclosing more and more of the secrets of its origin. Since the problem is in principal confined to the orbit, the various stages of development can be found in the orbital tissues, and in particular as lymphocytic infiltrations in the extraocular muscles. It has become almost certain that Graves' Disease is a complicated auto-immune disorder.
\end{abstract}

For more than 2 centuries doctors have been familiar with the disease called 'toxic goitre'. Swelling of the thyroid gland, tachycardia and tremors were recognised as a clinical entity many years ago.

It was at the beginning of the nineteenth century, in the days of Graves, of von Basedow and of Parry that exophthalmos was recognised as an extension of this disease. Although the relationship between the exophthalmos and the thyroid disorder became well established in the twentieth century, the real cause behind this exophthalmos was far from clear. To explain the massive oedematous swelling of the orbital contents, thyroxin intoxication was assumed.

Equally suspect as causes were, hyperexitation of the sympathetic nerves or even an exophthalmos producing hormone.

After the Second World War the true nature of thyroid metabolism was discovered. Thyroid Stimulation Hormone (TSH) appeared to be behind the production of thyroxin in the thyroid gland. The production of TSH in its turn, was regulated by a feed-back mechanism. TSH Releasing Hormone (TRH) was found to be responsible for the TSH dis- charge of the pituitary gland and eventually provided a very useful test to assess the function of the thyroid metabolism.

Hypertrophy of fat, oedema and lymphocytic infiltrates were generally acknowledged, but it was only after the development of the coronal CT-scan that the main target of the disease, the extraocular muscle, became visible and gave a true impression of the enormous swelling of the muscular tissue (Fig. 1). The massive lymphocytic infiltrates in the muscles and the impressive hypertrophy of fibroblasts and fibrocytes were seen to produce excess mucopolysaccharides as well as collagen fibres, followed by atrophy of the extraocular muscles and orbital fat. Consequently, the process ended in fibrosis and scar tissue.

Meanwhile it became evident that the orbit was a favoured site for lymphocytes. Not only in Graves' Disease, but equally in orbital pseudotumours, in Wegener's Granulomatosis in orbital myositis and sclero-tenonitis (Fig. 2). But it was in Graves' Disease and in Wegener's Granulomatosis that the extraocular muscles were so explicitly the primary target. 


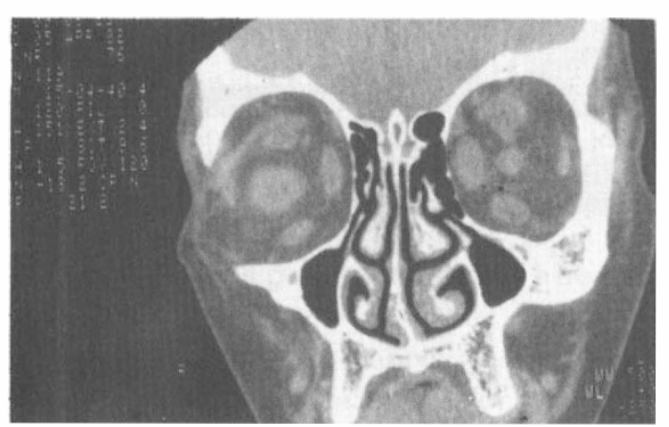

Fig. 1. The coronal CT-scan gives an excellent impression of the enormous swelling of the extra ocular muscles.

Why are the extraocular muscles such a particularly immune target?

Wieczorek et $a l^{1}$ found by investigating developmental transitions of myosin heavychain (MHC) gene expression in the rat extraocular musculature (EOM), six different MHC genes in extra ocular muscles. In addition, Sevel ${ }^{2}$ described at least six different types of fibres in extraocular muscles. There were slow, tenaciously contracting types of muscle fibres as well as twitch fibres and intermediate types, sometimes with a characteristic localisation at the inside or at the outside of the muscle.

In addition, antigens of thyroid origin were demonstrated in the extraocular muscle fibres by Konishin and co-workers by the binding of the thyroglobulin and anti-thyroglobulin immune complex to extraocular muscle membrane. ${ }^{3}$

These specific antigenic properties of the muscular fibres may finally give the clue as to why Graves' Disease is usually confined to the

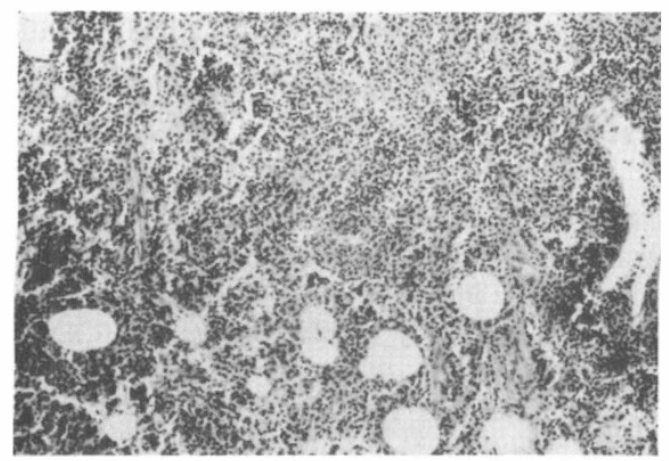

Fig. 2. Lymphocytic invasion of the orbit in Graves' Disease. orbit despite the well known exceptions such as pretibial dermopathy and thyroid acropachy in the fingertips.

\section{Damage by Graves' Disease}

Damage to the visual apparatus by overexposure of the anterior segment of the eye and diplopia because of infiltration of the extraocular muscles are easily understood.

Deterioration of the function of the optic nerve is no longer considered a consequence of toxic influence of hyperthyroidism but is regarded as a consequence of simple mechanical pressure on the optic nerve by the swollen extraocular muscle in the narrow apex of the orbit (Fig. 3). As a third factor, elevated intraorbital pressure can produce damage by local anoxemia.

This becomes all the more understandable after the study undertaken by Bergen ${ }^{4}$ of the vascular supply within the orbit.

Whereas Koornneef ${ }^{5}$ had made it clear that the orbit is subdivided in compartments surrounded by fibrous tissue (Fig. 4), it was Bergen who demonstrated the relationship that these compartments have with the intraorbital arteries and veins. The arteries neglect the anatomical divisions completely. They penetrate the septa and go directly to their destinations (Fig. 5).

The veins, on the other hand, follow the course that is directed by the walls of the compartments. (Fig. 6) The veins invariably are included in the structure of the septa by which the vessels are kept open, or in other words, prevented from collapsing under the intraorbital pressure, by the natural tension of the septa (Fig. 7), just like the jugular vein

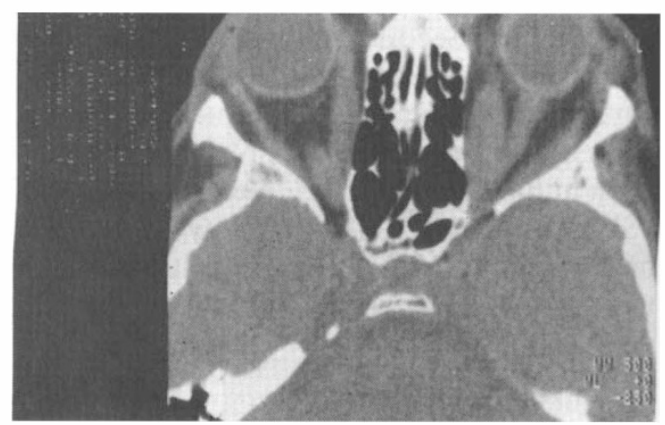

Fig. 3. Mechanical pressure on the optic nerve by the swollen extra ocular muscles. 


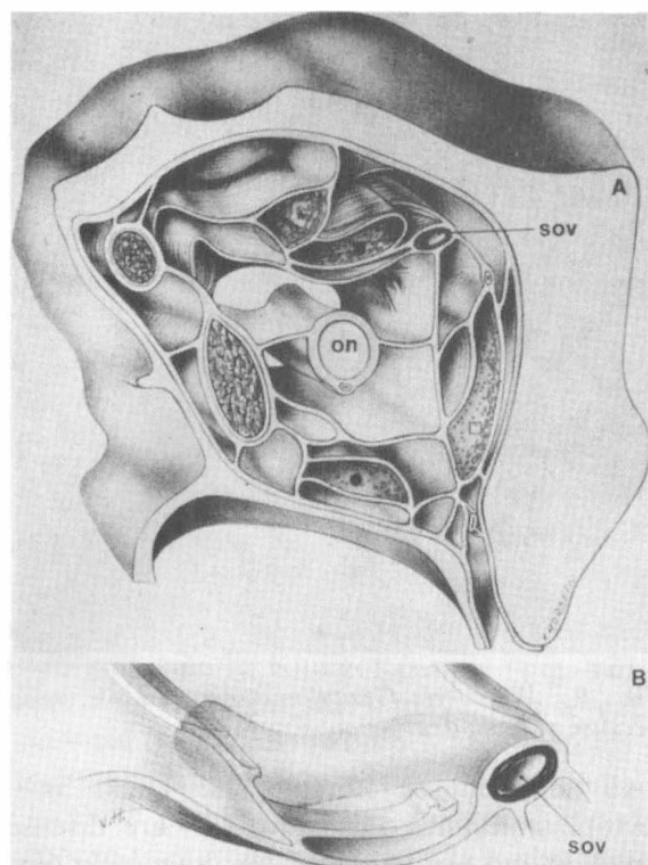

Fig. 4. The orbit is subdivided in compartments surrounded by fibrous tissue. (Courtesy Dr. Koornneef).

with its negative bloodpressure is kept open by supporting connective tissue strands and membranes on its course through the neck.

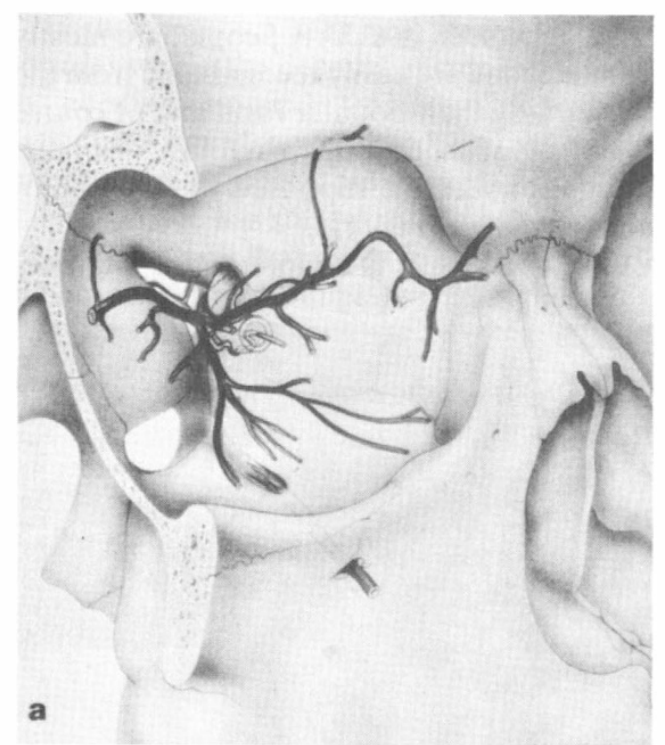

Fig. 5. The orbital arteries penetrate the septa and go directly to their eventual destination. (Courtesy Dr. Bergen)

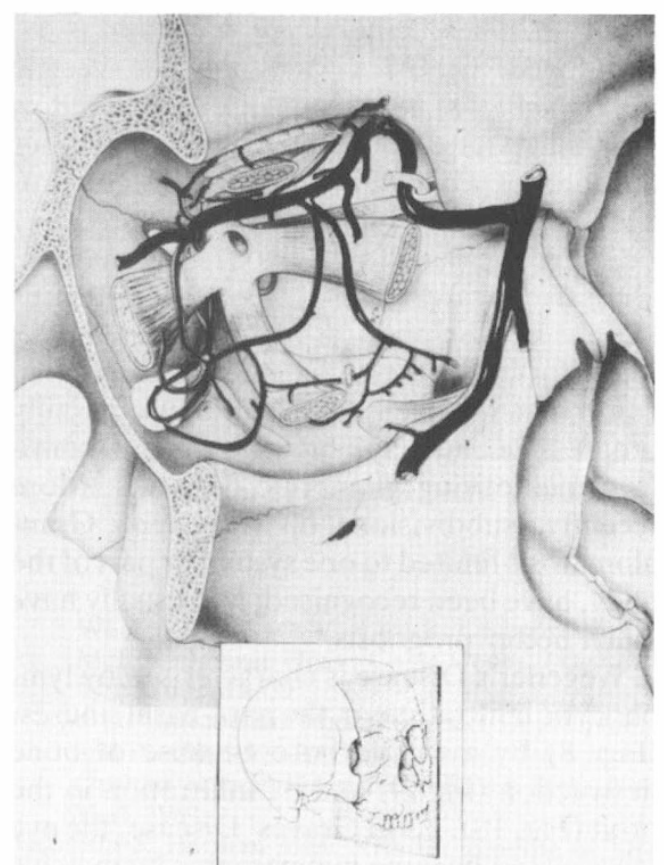

Fig. 6. The orbital veins are incorporated in the septa. They follow the walls of the compartments. (Courtesy Dr. Bergen)

It is easily understandable that the high intraorbital pressure in Graves' Disease can disrupt the delicate pressure regulation system of the orbital vascular supply, and that anoxemia must be added to the damaging factors within the orbit.

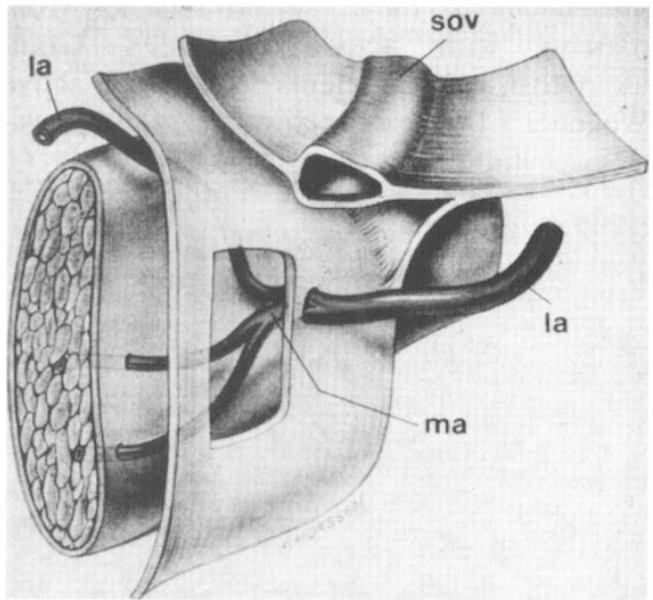

Fig. 7. The orbital veins are prevented from collapsing by the natural tension within the septa. (Courtesy Dr. Bergen) 


\section{Differential diagnosis}

Despite the fact that Graves' Disease is easily recognisable if at an advanced stage, it is sometimes hard to differentiate from other intraorbital processes, which can also be produced by lymphocytic invasion.

One of these is Wegener's Granulomatosis, a relatively rare form of necrotising angiitis located in the upper respiratory tract. It was called formerly, the 'lethal midline tumour', a name that was well deserved. It was rapidly progressive and death usually resulted from a focal necrotising glomerulo-nephritis. More recently, subdivisions of Wegener's Granulomatosis limited to one system or part of the body, have been recognised, and usually have much better prognosis. ${ }^{6}$

Wegener's Disease is characterised by lymphocytic infiltrations in the para-nasal sinuses, (Fig. 8) by a saddle nose because of bone destruction (Fig. 9) and by infiltration in the orbit (Fig. 10). As in Graves' Disease, the eye muscles can become hypertrophic by massive invasion of lymphocytes. The response to steroids is inadequate and temporary. In combination with cyclophosphamide, however, Wegener's Granulomatosis can be cured, at least in the more benign types.

Wegener's Disease was recently proved to be of autoimmune origin. Van der Woude, et $a l,{ }^{7}$ in 1985 wrote about an immunoglobulin G antibody against extra-nuclear compounds of polymorph-nuclear granulocytes, that was present in 25 of 27 serum samples from patients with active Wegener's Granulomatosis. In patients with non-active Wegener's Disease reactions were only posi-

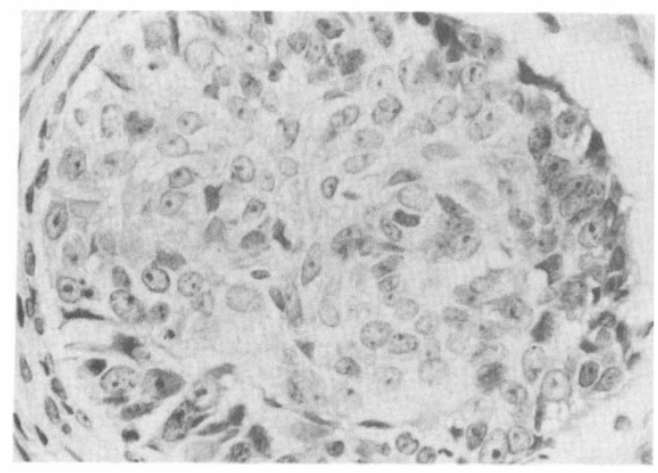

Fig. 8. Lymphocytic infiltrates in the para nasal sinusses in Wegeners Granulomatosis.

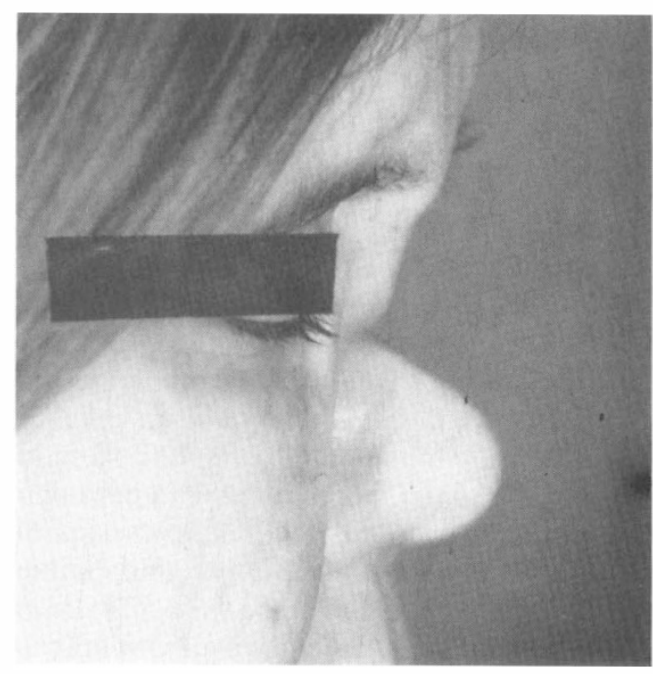

Fig. 9. Wegeners Granulomatosis. Saddle nose because of bone destruction.

tive in 4 out of 32 samples. These anticytoplasmic antibodies (ACPA) are disease specific and are valuable for diagnostic purposes well as for estimation of the activity of the disease.

Other lymphocytic invasions of the orbit have to be distinguished from Graves' Disease. Orbital pseudotumours for instance, consist of infiltrations with lymphocytes or granulocytes and usually plasma cells.

They are seen in elderly people, are mostly unilateral and are easily recognisable from the CT-scan, by their nodular form and of course by the absence of thyroid disorder. Pseudotumours are supposed to be of autoimmune origin (Fig. 11).

Orbital myositis is a more active immune-

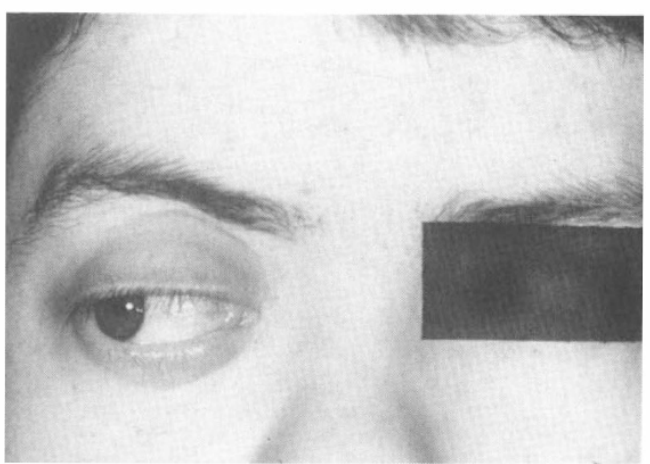

Fig. 10. Chronic infiltration in the sclera and in the orbit in a young woman with Wegeners disease. 


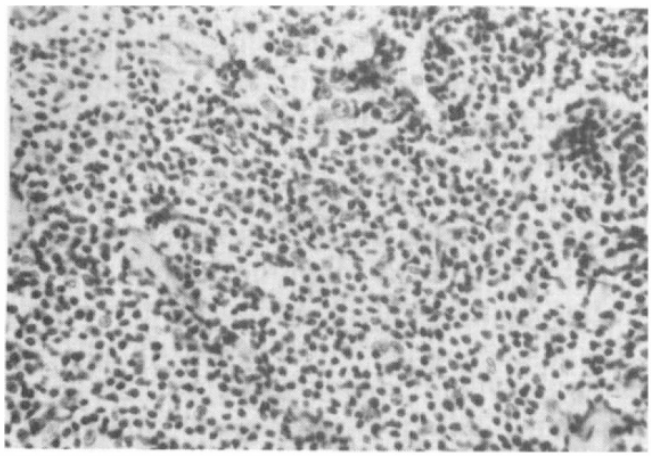

Fig. 11. Lymphocytic infiltrates in orbital pseudo tumour.

process situated in the anterior part of the orbit. It occurs in younger people (Fig. 12). Sometimes it is bilateral, it may cause severe pain and responds promptly to steroids. Sclero-tenonitis is closely related to myositis. It is more painful and has an equally good response to steroid treatment. It is also considered to be of auto-immune origin.

With respect to the spectacular advances achieved by the immunological approach to Graves' Disease, the time is ripe to solve the problem. I would not like to go as far as Bryan $\mathrm{R}$. Younge did after advocating the orbital decompression in Graves' Disease:

'Fortunately, we may see the end of this disorder within the decade, and no longer will be needing surgical treatment for these patients. Knoweldge of the definitive cause, and thus the cure, is close at hand'. ${ }^{8}$

This decade has still two and a half years to go, which means that we have to be in a hurry to help Bryan R. Younge prove his thesis.

\section{References}

1 Wieczorek DF, Periasamy M, Butler-Browne GS,

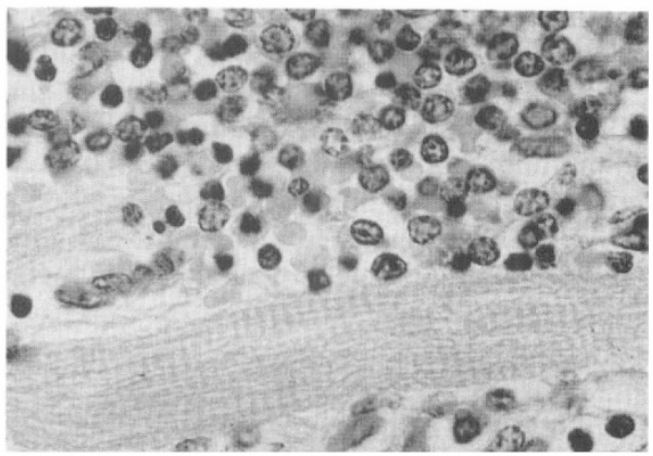

Fig. 12. Infiltration of the extra ocular muscle with lymphocytes in orbital myositis.

Whalen RG, Nadal-Ginard B: Co-expression of Multiple Myosin Heavy Chain Genes. J Cell Biol 1985, 100: 618-29.

${ }^{2}$ Sevel D: Extraocular Muscles: Their Development and Peculiarities. In Gorman et al: The Eye and Orbit in Thyroid Disease. Ed Raven Press, New York 1984.

${ }^{3}$ Konishi J, Herman MM, Kris JP: Binding of Thyroglobulin and Thyroglobulin-Antithyroglobulin Immune Complex to Extraocular Muscle Membrane. Endocrinology 1974, 95: 434-46.

${ }^{4}$ Koornneef L: Anatomy of the Orbit, Academic Thesis. Zwets and Zeitlinger, Lisse, 1978.

${ }^{5}$ Bergen MP: Vascular Architecture of the Orbit. Academic Thesis, pp 96, 98 and 107. 1982 Zwets and Zeitlinger, Lisse.

${ }^{6}$ Spalton DJ, Graham EM, Page NGR, Sanders MD: Ocular changes in limited forms of Wegener's granulomatosis. Br J Ophthalmol 1981, 65: 55363.

${ }^{7}$ Woude FJ van der, Lobatto S, Permin H, Giessen M van der, Rasmussen N, Wijk A, Es LA van, Hem GK van der, The TH: Autoantibodies against neutrophils and monocytes: Tool for diagnosis and marker of disease activity in Wegener's granulomatosis. Lancet 1985, i: 425-9.

${ }^{8}$ Younge BR: Eye Examination Techniques in Graves' Ophthalmopathy. In Gorman et al: The Eye and Orbit in Thyroid Disease. Ed. Raven Press, New York, 1984. 